\title{
Distribution pattern of swarm-founding eusocial wasps in the Indonesian Archipelago in comparison of that of parrots, one of sedentary bird groups
}

\author{
Machi Hanawa* and Jun-ichi Kojima \\ Natural History Laboratory, Faculty of Science, Ibaraki University, Mito, 310-8512 Japan
}

\begin{abstract}
In the colony founding modes, eusocial wasps are divided into "independent-founders", which initiate a colony by one to several inseminated females, and "swarm-founders", which found their new colony by a number of "workers" accompanying one to many "queens". As the swarm-founders put their trail pheromone on a guide to lead their colony members to a new nesting site, they would not disperse across large water bodies, such as sea and wide rivers. The present-day distribution pattern of swarmfounding wasps on the islands that are currently separated from each other and from continents should reflect the historical geology of these islands. The distribution patterns of the swarm-founding eusocial wasps in the Indonesian Archipelago are characterized by (1) occurrence of Asian continental elements in Borneo and Sumatra and their adjacent small islands, with a few species extending eastwards to Flores of Lesser Sunda Islands; (2) restriction of Australasian elements to New Guinea and its adjacent small islands including Aru; and (3) absence on most islands in Wallacea such as Sulawesi, Moluccas and eastern parts of Lesser Sunda Islands including Timor. These islands where no swarm-founders occur have never merged with any continental (Asian or Australasian) land mass. In the current distribution patterns in the Indonesian Archipelago, the swarm-founding eusocial wasps and the parrots are superficially similar, but their historical biogeography would be quite different.
\end{abstract}

\section{Introduction}

The Indonesian Archipelago, comprising of about 17,500 islands, may refer to the groups of islands within the territory of the Republic of Indonesia. In the sense of biogeography, however, "Indonesian Archipelago" may correspond to the Malay Archipelago (Indo-Australian Archipelago) excluding the Philippine Archipelago, simply because all the borders with Malaysia on Borneo Island, with East Timor on Timor Island and with Papua New Guinea on New Guinea Island may have no biological meaning. The Indonesian Archipelago is known as an archipelago of mega biodiversity consisting of both Oriental and Australasian elements, and includes the Wallacea, the area known as high endemism and encompassing a group of islands separated by deepwater straits from the Asian (Sunda) and Australian (Sahul) continental shelves. The makeup of the presentday terrestrial fauna of the archipelago at higher taxonomic levels could have been largely affected by the geological events occurred in the region in the past 50 million years and at species level by the dramatic changes in the sea level occurred in the Pleistocene having led to the sunder and fusion of islands in the archipelago [1,2]. Furthermore, small vertebrates and invertebrates may have accidentally dispersed with prehistoric human migration.

The three subfamilies in the hymenopteran family Vespidae, namely Stenogastrinae (hover wasps), Polistinae (paper wasps) and Vespinae (hornets, yellowjackets), have traditionally been considered to form a monophyletic group of eusocial wasps $[3,4,5]$. A recent phylogenetic study [6], on the other hand, showed that the eusociality evolved twice in the Vespidae, once in the Stenogastrinae, which are the most basal clade in the Vespidae and have eusociality with rudimentary female castes (queen/worker), and once in the common ancestor of the Polistinae and the Vespinae, which form the most terminal clade in the Vespidae and have eusociality with morphological castes.

Two modes of colony founding are recognized in eusocial wasps; one is the "independent-founding", in which a colony is founded by one to several inseminated females (potential "queens"), and the another is the "swarm-founding", where a new colony is founded by a number of "workers" accompanying one to many 


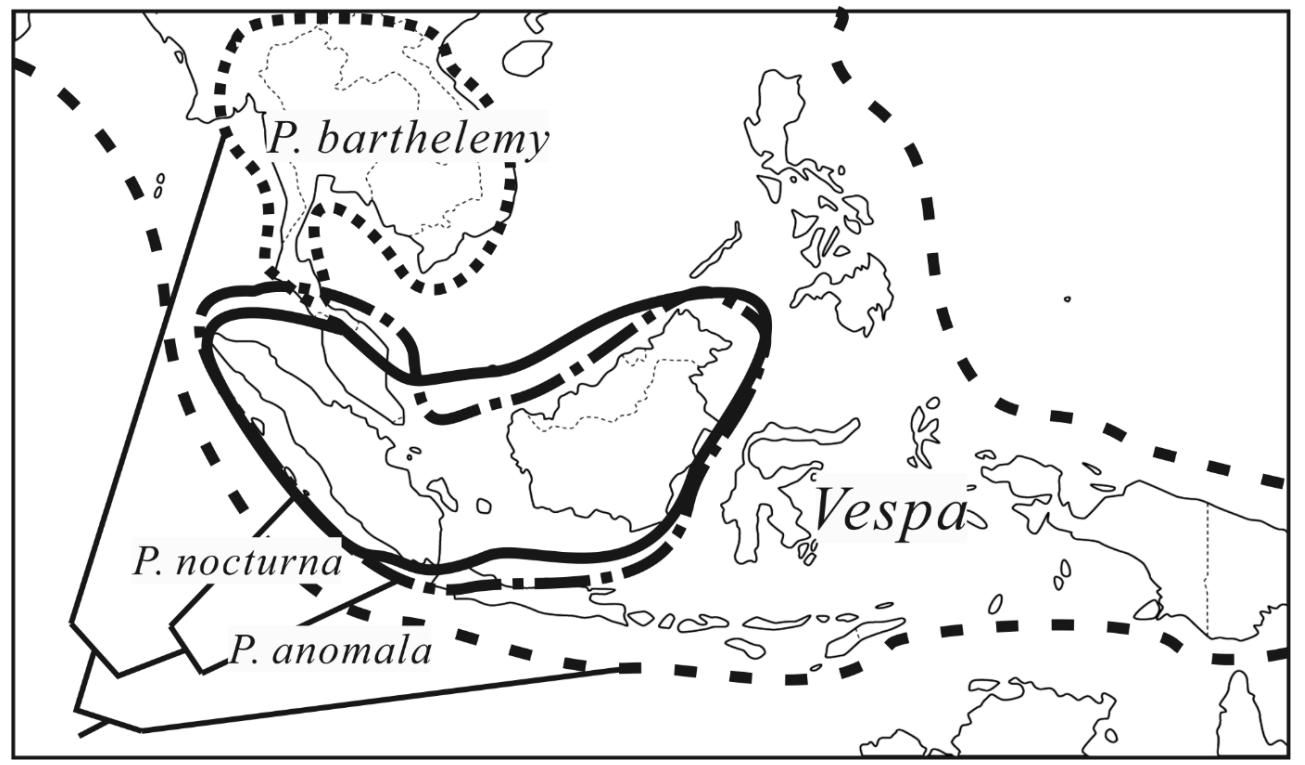

Fig. 1. Distribution ranges of Provespa species and its sister genus Vespa. Phylogenetic relationships among the three Provespa species are given in the form of cladogram.

"queens". As the workers of swarm-founders put their trail pheromone on a guide to lead their colony members (including queens) to a new nesting site, they would neither disperse across large water bodies, such as sea and wide rivers, nor with human movement. Consequently, the present-day distribution pattern of the swarm-founding wasps on the islands that are currently separated from each other and from continents should reflect the historical geography of these islands. All the species of the Stenogastrinae are the independentfounders, while both Polisitinae and Vespinae include both independent- and swarm-founders. In the Indonesian Archipelago, 120 species of Polistinae + Vespinae have been recorded [7] and they include those that are known to be swarm-founders.

Parrots belong to a lineage quite different from that of the eusocial wasps and thus may have different biogeographical history. Despite of their high potentiality for dispersal across water bodies, presentday distribution pattern of the Indonesian parrots, which are generally sedentary and are known to include many species/subspecies endemic to respective islands in the Indonesian Archipelago may reflects the historical geography of the archipelago [8].

In the present study, we analyzed the distribution patterns of the swarm-founding eusocial wasps in the Indonesian Archipelago with reference to phylogenetic relationships among the genera and the species-groups in the polistine genus Ropalidia. The process with which such the distribution patterns have been formed is discussed referring to the historical geography of the archipelago and in comparison of the distribution patterns of the Indonesian parrots.

\section{Material and Methods}

The data/information used in the present study, such as the distribution records and phylogenetic relationships, were obtained from the literature, websites and through personal communications.

For the distribution of the eusocial wasps the data used in this study were extracted mainly from Nugroho et al. [7]. Phylogenetic relationships among genera of the Polistinae and Vespinae were based on Pickett \& Carpenter [5] and Piekarski et al. [6], and those among species-groups of the polistine genus Ropalidia were based on Morooka-Saito (unpublished poster presentation in 2014). Distribution records of parrots were compiled by referring to Burung Nusantara [8] and Clements et al. [9]. The phylogeny and taxonomy of the parrots were based on Avian Phylogeny [10] and Provost et al. [11].

\section{Results and Discussion}

Swarm-founding eusocial wasps in the Vespinae are all the three species of the genus Provespa and those in the Polistinae are the New World tribe Epiponini, the genus Polybioides of the Old World tribe Ropalidiini and the following species groups of the Old World genus Ropalidia: malayana-group, sumatrae-group, flavopicta-group, maculiventris-group, nigra-group, lefebvrei-group and romandi-group. Referring to their phylogenetic relationships, swarm founding would have evolved independently five or six times in the eusocial wasps; respectively in the ancestors of Provespa, Epiponini, Polybioides and in the genus Ropalidia, malayana-group, (sumatrae-group + flavopicta-group) [or (malayana-group + (sumatrae-group + flavopictagroup))] and ((maculiventris-group + nigra-group) + (lefebvrei-group + romandi-group)) (Fig. 2).

All of these swarm-founding eusocial wasps except New World Epiponini occur in the Indonesian Archipelago. Two of the three Provespa species occur in Borneo and Sumatra and one of the two also occurs in western part of Java [12] (Fig. 1). 


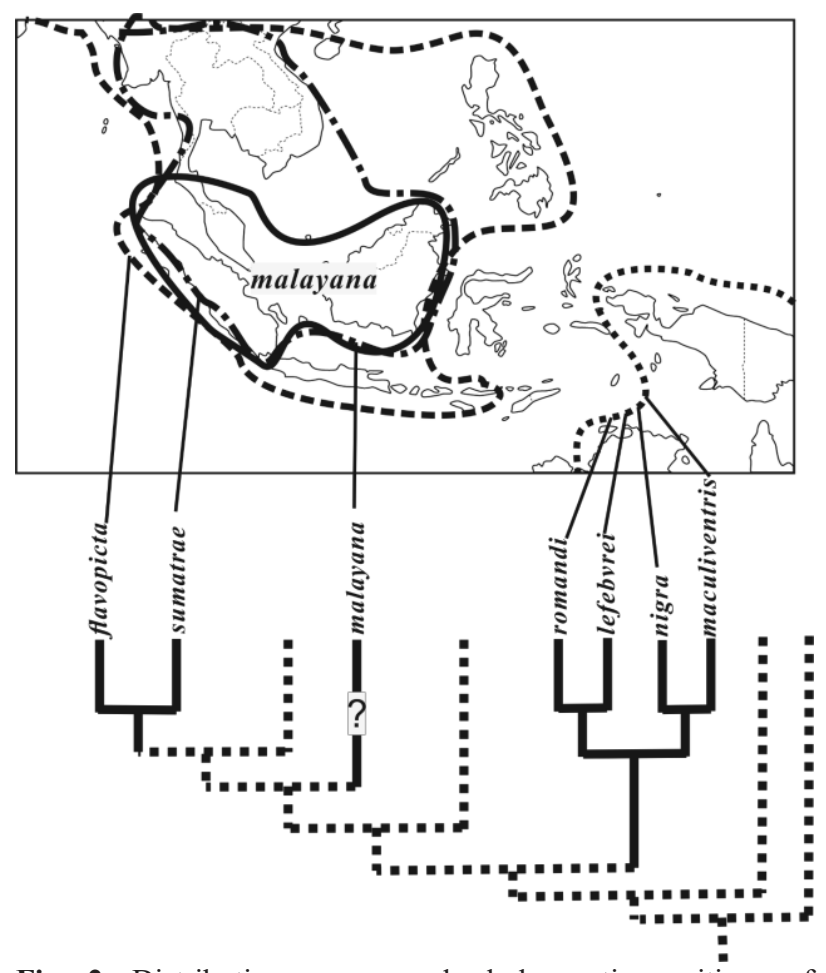

Fig. 2. Distribution ranges and phylogenetic positions of swarm-founding Ropalidia species-groups. Clades shown with solid lines are swarm-founders and those shown with dotted lines are independent-founders.

Polybioides has disjunct distribution, two species in tropical Africa and four species in Southeast Asia; two of the four Southeast Asian species occur in Malay Peninsula, Borneo and Sumatra. In Ropallidia, the malayana-group is distributed in Malay Peninsula, Borneo and Sumatra; the sumatrae-group in southeastern parts of Asian Continent, Borneo and Sumatra; and the flavopicta-group occurs from eastern part of Indian Subcontinent in the west to the Philippine Islands and Sumba and Flores of Lesser Sunda Islands in the east. Wasps of the maculiventris-, nigra-, lefebvrei- and romandi-group are distributed in New Guinea and its adjacent small islands (including Aru Islands) and northern parts of Australia.

As shown above, the distribution patterns of the swarm-founding eusocial wasps in the Indonesian Archipelago are characterized by (1) occurrence of Asian continental elements (Provespa, Polybioides, the malayana-, sumatrae- and flavopicta-group of Ropalidia) in Borneo and Sumatra and their adjacent small islands, with a few species extending eastwards to Flores of Lesser Sunda Islands; (2) restriction of Australasian elements (the maculiventris-, nigra-, lefebvrei- and romandi-group of Ropalidia) to New Guinea and its adjacent small islands including Aru; and (3) absence on most islands in Wallacea such as Sulawesi, Moluccas and eastern parts of Lesser Sunda Islands including Timor.

Although the eastward extension of the Ropalidia flavopicta-group to Lesser Sunda Islands beyond the deep-water strait between Bali and Lombok and the disjunct distribution of Polybioides in Africa and Southeast Asia are yet puzzling, the distribution patterns of the swarm founding eusocial wasps in the Indonesian Archipelago could generally be explained in the context of historical geography of the archipelago and the assumption that swarm founding evolved multiple times possibly relatively recently (in the Pliocene or even Pleistocene, when the islands and land masses were nearly at the current positions) in the Southeast Asian lineages (Provespa, clade(s) of Ropalidia) and once possibly at older time (in the Eocene or even older) in an Australasian lineage (clade of Ropalidia). Namely the islands where no swarm-founders occur have never merged with any continental (Asian or Australasian) land mass.

Showing distribution pattern in the Indonesian Archipelago generally similar to that of the swarmfounding eusocial wasps, comparison with the distribution pattern of parrots, of which historical biogeography has been much better studied than that of eusocial wasps, may help us to better understand the historical biogeography of the swarm-founding eusocial wasps in the Indonesian Archipelago.
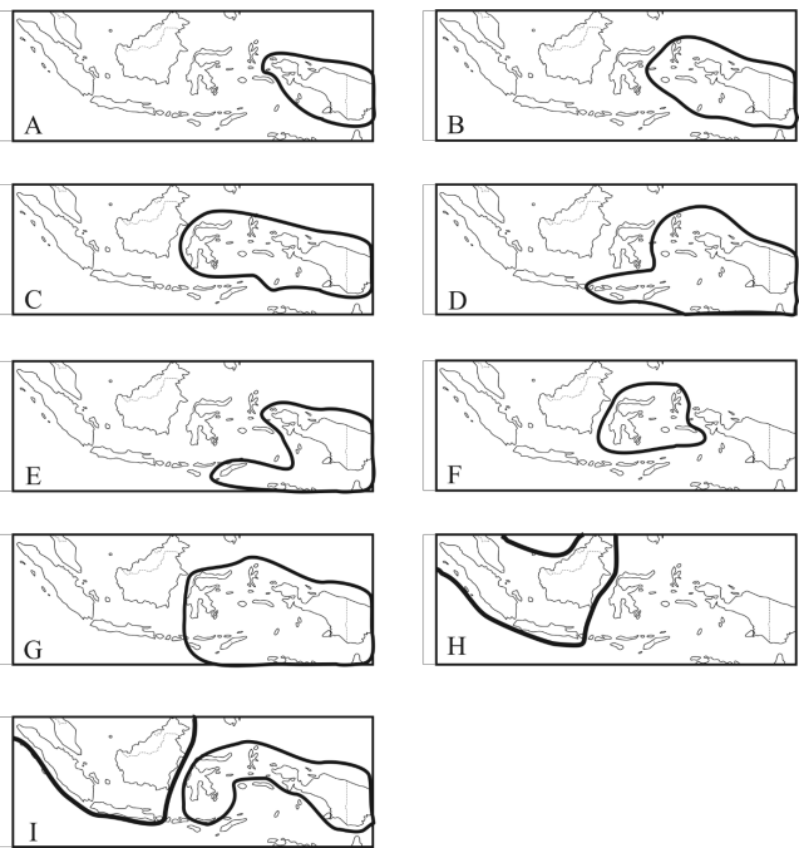

Fig. 3. Distribution ranges of parrot genera in the Indonesian Archipelago. A. Psittrichas in the Psittrichasinae, Chalcopsitta, Pseudeos, Oreopsittacus, Neopsittacus, Cyclopsitta and Psittaculirostris in the Loriinae, Psittacella in the Psittacellinae, and Probosciger in the Cacatuinae. B. Eos, Lorius and Charmosyna in the Loriinae, and Micropsitta in the Psittaculinae. C. Alisterus in the Psittaculinae. D. Psittenteles in the Loriinae, and Geoffroyus and Eclectus in the Psittaculinae. E. Aprosmictus in the Psittaculinae. F. Prioniturus in the Psittaculinae. G. Trichoglossus in the Loriinae, Tanygnathus in the Psittaculinae, and Cacatua in the Cacatuinae. H. Psittinus and Psittacula in the Psittaculinae. I. Loriculus in the Agapornithinae.

Parrots (Psittaciformes) are considered Gondwanan origin during the Cretaceous or in the Eocene (47.4 MYA) [13,14]. Based on the current distribution patterns, parrots in the Indonesian Archipelago can be divided into Australasian (22 genera and most species of 
Loriculus) and Southeast Asian (Psittinus, Psittacula and two species of Loriculus) elements. While nine genera of Australasian elements are confined to New Guinea in their current distribution, others (but Prioniturus distributed only in Moluccas and Sulawesi) are distributed also on the islands in Wallacea (Fig. 3) as species and/or subspecies endemic to respective islands.

Unlike the swarm-founding eusocial wasps, parrots would have flight ability sufficient to disperse across water-bodies. The Southeast Asian elements are also considered Australasian origin and their multiple trans-oceanic dispersals to Southeast Asia (Sunda Land) from Australasia probably occurred 20-25 MYA [15].

In the current distribution patterns in the Indonesian Archipelago, the swarm-founding eusocial wasps and the parrots are superficially similar, but their historical biogeography would be quite different. Further intensive studies on phylogenetic relationships among Old World polistine genera (especially, to explain the disjunct distribution of Polybioides) and species-groups of Ropalidia should contribute to our better understanding of the biogeography of the swarm-founding eusocial wasps in the Indonesian Archipelago.

\section{Conclusion}

Swarm-founding eusocial wasps found a new colony a number of "workers" accompanying one to many "queens" and the workers put their trail pheromone on a guide to lead their colony members (including queens) to a new nesting site, and thus they would not be able to disperse across large water bodies, such as sea and wide rivers. Swarm-founding eusocial wasps distributed in the Indonesian Archipelago (Provespa, Polybioides and Ropalidia) can be divided into the Asian Continental and Australasia elements. Asian Continental elements occur in Borneo and Sumatra, with a few species extending eastwards to Flores of Lesser Sunda Islands, and Australasia elements are confined in their distribution to New Guinea including Aru Islands. Swarm-founding eusocial wasps are absent in the islands of Wallacea. Such the present-day distribution patterns of the swarmfounding eusocial wasps can be the results of historical geography of the Indonesian Archipelago, where the islands of Wallacea have never merged with any continental (Asian or Australasian) land mass. In the current distribution patterns in the Indonesian Archipelago, the swarm-founding eusocial wasps and the parrots are superficially similar, but their historical biogeography would be quite different and such superficial similarity would not be explained in the same context.

We thank Hari Nugroho for his valuable suggestions given to us while we were carrying out the present study.

\section{References}

1. D.J. Lohman, M. de Bruyn, T. Page, K.von Rintelen, R. Hall, K.L. Peter Ng., H. Shih, G.R. Carvalho, T.von Rintelen, Annu Rev Ecol Evol S 42: 205-226 (2011)

https://doi.org/10.1146/annurev-ecolsys-102710145001

2. R. Hall, Annu Rev Earth Pl Sc 45: 331-358 (2017) https://doi.org/10.1146/annurev-earth-063016020633

3. O.W. Richards, Biol Rev 46 (4) : 483-528 (1971) https://doi.org/10.1111/j.1469185X.1971.tb01054.X

4. J.M. Carpenter, Syst Entomol 7 (1): 11-38 (1982) https://doi.org/10.1111/j.1365$\underline{\text { 3113.1982.tb00124.x }}$

5. K.M. Pickett \& J.M. Carpenter, Arthropod Syst Phylo 68: 3-33 (2010)

6. P.K. Piekarski, J.M. Carpenter, A.R. Lemmon, E.M. Lemmon, B.J. Sharanowski, Mol Biol $\begin{array}{lllll}\text { Evol } & 35 & \text { (9) : } & 2097-2109 & \text { (2018) }\end{array}$ https://doi.org/10.1093/molbev/msy124

7. H. Nugroho, J. Kojima, J.M. Carpenter, $\begin{array}{llll}\text { Treubia } & 38 \text { : } & 71-186 & \text { (2011) }\end{array}$ http://dx.doi.org/10.14203/treubia.v38i0.547

8. Burung Nusantara. http://burungnusantara.org/birding-indonesia/checklist-birds-ofindonesia/ $\left[\right.$ accessed on $31^{\text {th }}$ December 2019] (2019)

9. J.F. Clements, T.S. Schulenberg, M.J. Iliff, S.M. Billerman, T.A. Fredericks, B.L. Sullivan, C.L Wood.

https://www.birds.cornell.edu/clementschecklist/do wnload/ [accessed on $1^{\text {st }}$ December 2019] (2019)

10. Avian Phylogeny. https://www.birdphylogeny.de/superorders/australaves/psittacifomes I [accessed on 30 ${ }^{\text {th }}$ December 2019] (2019)

11. K.L. Provost, L. Joseph, B.T. Smith, Emu Austral $\begin{array}{llll}\text { Ornithology } & 118 & \text { (1) : 7-21 }\end{array}$ https://doi.org/10.1080/01584197.2017.1387030

12. F. Saito \& J. Kojima, Species Diversity $16: 65-74$ (2011)

13. N.E. White, M.J. Phillips, M.T.P. Gilbert, A. Alfaro-Nunez, E. Willerslev, P.R. Mawson, P.B.S. Spencer, M. Bunce, Mol Phylo Evol 59 : 615-622 (2011) https://doi.org/10.1016/j.ympev.2011.03.011

14. T.F. Wright, E.E Schirtzinger, T. Matsumoto, J.R. Eberhard, G.R. Graves, J.J. Sanchez, S. Capelli, H. Muller, J. Scharpegge, G.K. Chambers, R.C. Fleischer, Mol Biol Evol 25 (10) : 2141-2156 (2008) https://doi.org/10.1093/molbev/msn160

15. M. Schweizer, O. Seehausen, M. Güntert, s.t. Hertwig, Mol Phylo Evol 54 : 984-994 (2010) https://doi.org/10.1016/j.ympev.2009.08.021 